\title{
TRABALHO DO PRODUTOR AGRÍCOLA URBANO E PERIURBANO: HORTICULTORES DO CENTRO-SUL PIAUIENSE
}

\author{
Marttem Costa de Santana ${ }^{1}$ \\ Everardo de Sousa Luz ${ }^{2}$ \\ Maurício Ribeiro da Silva ${ }^{3}$ \\ Maclovia Corrêa da Silva ${ }^{4}$ \\ Eloy Fassi Casagrande Junior ${ }^{5}$
}

\section{Resumo}

Este trabalho versa sobre a agricultura urbana e periurbana piauiense. $\mathrm{O}$ objetivo foi avaliar se as condições de trabalho do produtor agrícola urbano e periurbano contribuem para a produção de alimentos na cidade. Esta atividade social, política e econômica tem pouca visibilidade nas cidades e as condições de trabalho podem ser melhoradas. A pesquisa de campo para coleta de dados, com abordagem qualitativa, abarca uma realidade específica de duas cidades do estado do Piauí. Para os dados coletados foi priorizada a técnica da análise de conteúdo. Conclui-se ser necessária a participação do poder público para suprir falhas no sistema de produção agrícola em pequena escala visando ampliar as condições de trabalho dos horticultores urbanos. Sugere-se a promoção de palestras, cursos de capacitação técnica, relações humanas no trabalho, noções de primeiros socorros e noções de comercialização.

Palavras-chave: Agricultura urbana e periurbana, produção de alimentos, horticultores.

\footnotetext{
${ }^{1}$ Doutorando em Tecnologia e Sociedade pela Universidade Tecnológica Federal do Paraná (UTFPR) e professor da Universidade Federal do Piauí. E-mail: amigomcs@ hotmail.com.

${ }^{2}$ Doutorando do Programa de Pós-graduação em Tecnologia e Sociedade da Universidade Tecnológica Federal do Paraná (UTFPR) e professor do Ensino Básico Técnico e Tecnológico no Colégio Técnico de Floriano (CTF), escola de educação profissional e tecnológica vinculada à Universidade Federal do Piauí. E-mail: heverluz@hotmail.com.

${ }^{3}$ Doutorando em Tecnologia e Sociedade pela Universidade Tecnológica Federal do Paraná (UTFPR) e professor do Colégio Técnico de Bom Jesus vinculado a Universidade Federal do Piauí. E-mail: mauricioribeiro@ufpi.edu.br.

${ }^{4}$ Docente permanente do Programa de Pós-graduação em Tecnologia e Sociedade da Universidade Tecnológica Federal do Paraná (UTFPR). E-mail: macloviasilva@utfpr.edu.br.

${ }^{5}$ Docente permanente do Programa de Pós-graduação em Tecnologia e Sociedade da Universidade Tecnológica Federal do Paraná (UTFPR). E-mail: eloy.casagrande@ gmail.com.
}

Sociedade e Território - Natal. Vol. 29, N. 2, p. 132-153, Jul./Dez. de 2017. 


\title{
WORK OF URBAN AND PERIURBAN AGRICULTURAL PRODUCERS: HORTICULTANTS OF CENTRAL SOUTHERN PIAUIENSE
}

\begin{abstract}
This paper deals with urban and periurban agriculture in Piauí. The objective was to evaluate if the working conditions of urban and periurban agricultural producers contribute to the production of food in the city. This social, political and economic activity has little visibility in cities and working conditions can be improved. The field survey for data collection, with a qualitative approach, covers a specific reality of two cities in the state of Piauí. For the collected data the technique of content analysis was prioritized. It is concluded that the participation of the public power is necessary to overcome failures in the system of smallscale agricultural production in order to increase the working conditions of urban horticulturists. It is suggested the promotion of lectures, technical training courses, human relations at work, notions of first aid and notions of commercialization.
\end{abstract}

Key-words: Urban and peri-urban agriculture, food production, horticulturists.

\section{TRAVAIL DES PRODUCTEURS AGRICOLES URBAINS ET PÉRIURBAINS: HORTICULTES DE LA PIAUIENSE CENTRALE DU SUD}

\section{Resume}

Cet article traite de l'agriculture urbaine et périurbaine au Piauí. L'objectif était d'évaluer si les conditions de travail des producteurs agricoles urbains et périurbains contribuent à la production de nourriture dans la ville. Cette activité sociale, politique et économique a peu de visibilité dans les villes et les conditions de travail peuvent être améliorées. L'enquête sur le terrain pour la collecte de données, avec une approche qualitative, couvre une réalité spécifique de deux villes dans l'état du Piauí. Pour les données collectées, la technique d'analyse de contenu a été classée par ordre de priorité. On conclut que la participation du pouvoir public est nécessaire pour surmonter les échecs dans le système de production agricole à petite échelle afin d'accroître les conditions de travail des horticulteurs urbains. Il est suggéré de promouvoir des conférences, des cours de formation technique, des relations humaines au travail, des notions de premiers secours et des notions de commercialisation.

Mot-clés: Agriculture urbaine et periurbaine, production alimentaire, horticulteurs.

\section{AGRICULTURA NO BRASIL}

A concepção portuguesa sobre o território brasileiro nos séculos XVII e XVIII era que terreno inculto não tinha significado. Por isso, a agricultura em território brasileiro, conhecida como a de ciclos de grandes monoculturas, e o extrativismo duraram séculos. Começou com o pau-brasil, a cana-de-açúcar, o algodão e o tabaco, cujo comércio de exportação era 
organizado e controlado pela Coroa Portuguesa. A atividade agrícola de subsistência visava atender as pequenas demandas dos moradores das aldeias.

A agricultura de subsistência é responsável, então, por fazer conviverem, na colônia, dois modelos de relação de trabalho e exploração da terra. [...]. Dentre os gêneros cultivados para consumo interno, podemos destacar o feijão, o milho, o arroz e, sobretudo, a mandioca, que logo se tornou a base da alimentação colonial (BARCELOS, 2010, p. 64-65).

A decadência do ciclo da mineração e as culturas concorrentes nas colônias de outros países da Europa direcionaram a Coroa Portuguesa a buscar meios para implantar indústrias. Todavia, na metade do século XIX, a mão de obra era exclusivamente formada de escravos. A vinda de imigrantes para cultivar o café, o cacau e explorar os recursos da Amazônia, concomitantemente com o fim do tráfego negreiro em 1850, mudou o quadro da oferta e demanda de alimentos. Evidenciam-se duas grandes correntes migratórias, uma de "origem europeia para a região cafeeira, o Brasil conheceu no último quartel do século XIX e primeiro decênio do $\mathrm{XX}$, outro grande movimento de população: da região nordestina para a amazônica" (FURTADO, 2003, p. 130).

Na entrada do século XX, havia um paradoxo entre o uso das técnicas de mecanização no cultivo a serem utilizadas nas grandes lavouras e na agricultura de subsistência. Fomentavam-se as desconfianças e os temores quanto à apropriação da tecnologia, adequação ao plantio, e ao funcionamento preciso das máquinas, que poderiam prejudicar a planta. “Temiam as inovações já que não poderiam plantar seu milho e feijão nas ruas dos cafezais devido às máquinas" (HENRIQUES, 2011, p. 365).

As técnicas e as tecnologias trouxeram certos benefícios para a humanidade, apesar das dificuldades de acesso, aquisição e ao uso.

\footnotetext{
Foi através do desenvolvimento tecnológico que os seres humanos encontraram formas para atender sua necessidade de controlar e dominar a natureza. Os exemplos são ricos nos mais variados domínios: a agricultura como forma de controle na oferta de alimentos; técnicas para o controle dos fenômenos atmosféricos e climáticos; técnicas de cura para o controle de fenômenos relacionados à saúde/doença, técnicas para a extração/exploração dos recursos da natureza. Neste processo, há o estabelecimento de relações sociais, que são fundamentais para a produção e o desenvolvimento das técnicas (CARVALHO, 1998, p. 64).
}

A difusão das técnicas de pesquisa agrícola em nível mundial permitiu o compartilhamento de saberes, conhecimentos, práticas e insumos. Os investimentos na produção de grande escala, com produtividade e lucro caracterizaram a chamada "Revolução 
Verde" ${ }^{6}$ que visava aumentar a produção de alimentos compatível ao crescimento populacional. Ela também trouxe aspectos negativos, como as monoculturas e comprometimento da capacidade de carga do Planeta. Ela começou em 1943, selada pelo evento da criação do Escritório de Estudos Especiais ${ }^{7}$ e a Fundação Rockfeller com o objetivo de melhorar o rendimento do milho, trigo e feijão. A expressão "Revolução Verde" foi criada em 1966, em uma conferência nos Estados Unidos.

\begin{abstract}
Um objetivo consciente da Revolução Verde, desde o início, era produzir variedades que pudessem ser cultivadas num amplo leque de condições em todo o mundo em desenvolvimento. Para atingir esse objetivo, os produtores do México haviam cultivado, com êxito, os novos tipos de trigo para serem indiferentes ao fotoperiodismo, isto é, eles poderiam florescer e produzir grãos em qualquer época do ano, ao contrário de variedades tradicionais que tendem a florescer em certas estações. Contanto que a temperatura ficasse acima de determinado grau mínimo e houvesse água suficiente, as novas variedades cresceriam em quase toda parte (MATOS, 2010, p. 3-4).
\end{abstract}

Este processo de modernização agrícola chegou ao Brasil nas décadas 1960-1970 por meio de créditos, pacotes tecnológicos e subsídios para fomentar a agroindústria, as empresas de máquinas, insumos agrícolas e a exportação e exclui a agricultura familiar. Com o apoio das pesquisas da Revolução Verde e por meio da "difusão internacional das técnicas de pesquisa agrícola, marca uma maior homogeneização do processo de produção agrícola em torno de um conjunto compartilhado de práticas agronômicas e de insumos industriais genéricos" (MATOS, 2010, p. 2).

O crescimento da produtividade agrícola, dos produtos químicos e do melhoramento de sementes introduziram variedades como o milho, o trigo e o arroz. No discurso ideológico, sempre está presente a ideia da "fome zero" ". A Revolução Verde viria a criar novas técnicas de plantio e novas sementes - as sementes milagrosas. O programa origina uma superprodução de alimentos, acima da expectativa (A MORTE DO MAR, 1969, p. 9). Esta revolução:

\footnotetext{
${ }^{6}$ A expressão Revolução Verde foi criada em 1966, em uma conferência em Washington, por William Gown, que disse a um pequeno grupo de pessoas interessadas no desenvolvimento dos países com déficit de alimentos "é a Revolução Verde, feita à base de tecnologia, e não do sofrimento do povo" (DUNCK, 2015, p. 51).

${ }^{7}$ Criado pelo Ministério da Agricultura do México para abrigar cientistas americanos e mexicanos que fizeram pesquisas sobre as culturas alimentares (MATOS, 2010).

${ }^{8}$ O programa Comunidade Solidária foi constituído em 1995 para atender a população que não tem condições para prover seu sustento, em especial o combate à fome e à pobreza. As ações governamentais se fixam nas áreas de alimentação e nutrição, serviços urbanos, desenvolvimento rural, geração de emprego e renda, defesa de direitos e promoção social (BRASIL, 1995b).
}

Sociedade e Território - Natal. Vol. 29, N. 2, p. 132-153, Jul./Dez. de 2017. 
[...] É um modelo baseado no uso intensivo de agrotóxico e fertilizantes sintéticos na agricultura. É um conjunto de estratégias e inovações tecnológicas que teve como escopo alcançar maior produtividade através do desenvolvimento de pesquisas em sementes, fertilização de solos, utilização de agrotóxicos e mecanização agrícola. (SERRA et al., 2016, p. 4).

Em 1969, o jornal carioca "Correio da Manhã" publicou uma notícia intitulada "A Morte do Mar", no qual discorreu sobre as implicações da Revolução Verde. O ecologista dr. Paul Ehrlich ${ }^{9}$ previa a poluição da água e do ar com a diminuição da incidência dos raios do sol, a resistência das pragas aos venenos, dificuldade para a fotossíntese das plantas e sobrevivência de animais que se alimentariam delas. Os inseticidas, como o DDT e o Thanodrin são agressores químicos com efeitos letais para o Homem. "O dr. Paul Ehrlich diz que o homem estava destruindo não apenas a fonte de alimentação, mas também o sistema de suporte de vida do planeta Terra" (A MORTE DO MAR, 1969, p. 9).

Além disso, Farias (2015) explica que este modelo agrícola que é liderado por insumos químicos, mecânicos e biológicos (transgênicos) foi responsável pela formação do capital e não respondeu a sua função primeira que seria ampliar a oferta de alimentos em grande escala. Tempo de produção se confunde com tempo de mercado, tempo de cultivo e sazonalidade foram alterados por hormônios, clonagem, melhoramento genético, poda, irrigação, e adaptação climática. Os programas de energia sustentáveis e as mudanças climáticas, o desmatamento, o aumento das áreas de pasto para a criação de gado modificaram a ocupação do território nacional. Lavouras de biocombustíveis competem com a produção alimentícia.

\begin{abstract}
Ao analisarmos o cenário brasileiro, país que apresenta representatividade na produção de alimentos a nível mundial, percebe-se que a produção e a disponibilidade de alimentos em quantidade suficientes não são sinônimos de segurança alimentar de uma população. A produção industrial de alimentos distante das relações pessoais de convívio tem retirado das relações humanas um valioso momento de desenvolvimento, que lhe é essencial, para solidez das sedes de solidariedade, e cumplicidade afetiva (DERANI, 2006). Além disso, nota-se também uma redução na variedade dos próprios alimentos produzidos, pois, o modelo modernamente aplicado não valoriza esta diversidade, acarretando problemas tanto de natureza alimentar, social, bem como ambiental (FARIAS, 2015, p. 76).
\end{abstract}

O modo de produção familiar e as práticas tradicionais foram retomados em novos moldes com o discurso de segurança alimentar, diversidade de produtos, quantidade e qualidade aprimorados e reavivamento das relações entre o ser humano, meio ambiente e a sociedade.

\footnotetext{
${ }_{9}^{9}$ O Dr. Paul Ehrlich é ecologista, professor de biologia da Universidade de Stanford e autor do livro "A População da Bomba" (A MORTE DO MAR, 1969, p. 9).
}

Sociedade e Território - Natal. Vol. 29, N. 2, p. 132-153, Jul./Dez. de 2017. 
Os 193 países membros da Organização das Nações Unidas (ONU) reconheceram em 2014 o papel da agricultura familiar como meio de incrementar a oferta de alimentos, garantir a biodiversidade e sustentabilidade do planeta.

A mão de obra da própria família é um fato relevante, bem como a contratação de empregados que corresponde "a sete de cada dez pessoas ocupadas no campo". No Brasil, a agricultura familiar, ocupando pequenas áreas de terra, produz os alimentos básicos como " $87 \%$ da mandioca, $70 \%$ do feijão, $46 \%$ do milho, $34 \%$ do arroz, $58 \%$ do leite, $59 \%$ da carne suína e 50\% das aves produzidas no campo" (COSTA, 2016, p. 2). O foco da Organização das Nações Unidas para a Alimentação e Agricultura teve quatro objetivos básicos para 2014:

1. Apoiar a formulação de políticas agrícolas, ambientais e sociais que promovam a agricultura familiar sustentável 2. Aumentar o conhecimento, a comunicação e conscientização pública 3. Obter um melhor entendimento das necessidades, do potencial e das restrições da agricultura familiar, e assegurar apoio técnico 4. Criar sinergias para a sustentabilidade (ORGANIZAÇÃO DAS NAÇÕES UNIDAS PARA A ALIMENTAÇÃO E AGRICULTURA, 2014).

A ONU incluiu na agricultura familiar as seguintes atividades do desenvolvimento rural: agrícola, florestal, pesqueira, pastoril e aquícola. As famílias são responsáveis pela mão de obra e pela produção de alimentos conforme as condições agroecológicas, características territoriais, culturais, acesso à terra, à educação especializada, aos recursos naturais, à tecnologia, aos financiamentos e aos serviços. Em 2016, em função do acordo de Paris e da Agenda de 2030 para o Desenvolvimento Sustentável, a ONU centrou seus esforços nas relações entre agricultura e mudanças climáticas que ameaçam a segurança alimentar. Problemas como aumento dos preços e disponibilidade de alimentos, redução da produtividade dos cultivos, poluição do ar e do solo podem comprometer o futuro do planeta.

Las políticas, las fuerzas del mercado y las limitaciones medioambientales
determinan la utilización de insumos y otros recursos en la agricultura, influyendo
en la productividad y el grado de conservación o agotamiento de los recursos
naturales. La formulación de políticas para la agricultura en el marco del cambio
climático debería partir de una comprensión de esos factores determinantes y de sus
repercusiones en los medios de vida de los agricultores y el medio ambiente
(ORGANIZACIÓN DE LAS NACIONES UNIDAS PARA LA ALIMENTACIÓN
Y LA AGRICULTURA, 2016, p. 16).

A seleção e o melhoramento genético têm sido uma opção para aumentar a produção de alimentos, mas ainda faltam pesquisas para se conhecer as consequências do uso destas sementes e, os produtos do setor agroquímico para a saúde e o meio ambiente. Estes procedimentos têm origem nas experiências humanas de cruzar plantas e animais para 
produzir outras variedades, e "se até os dias de hoje [o Homem] não havia ainda misturado genes de espécies diferentes é porque não sabia como fazê-lo" (MERCADANTE, 1999, p. 77).

\section{PROCEDIMENTOS METODOLÓGICOS DA PESQUISA}

Trata-se de um estudo de experiências humanas que opera com diferentes métodos de trabalho, estilos e análise de resultados. A delimitação do tema de estudo refere-se ao espaço de hortas urbanas e periurbanas existentes em 2017, nas cidades de Floriano e Bom Jesus. O critério de escolha das cidades levou em conta o fato de ambas possuírem escolas de educação profissional vinculadas à Universidade Federal do Piauí (UFPI). Foram selecionadas hortas vinculadas às ações de prefeituras, de instituições religiosas e particulares. A entrevista aberta, individual e a observação de campo, naturalística ou sistemática, são estratégias de produção de dados para esta investigação. Todas as entrevistas ocorreram nos respectivos locais da pesquisa em contato direto com as pessoas, as quais interagem, interpretam, constroem sentidos e significados para as coisas e os seres vivos. Todavia, os pesquisadores trabalharam com a objetividade dos fatos para compreender e analisar os dados. Os depoimentos foram transcritos, com tempo estimado de 50 minutos para cada entrevistado.

Elegemos como critérios de Inclusão: ser agricultor(a) urbano(a) e periurbano(a) participante de hortas selecionadas (Floriano e Bom Jesus). E de exclusão: horticultores terceirizados (trabalhadores que eventualmente prestam serviços às hortas). As perguntas organizadas para serem aplicadas aos entrevistados apresentam riscos mínimos de possibilidades de constrangimento, contrariedades e desconfortos inesperados de natureza psíquica, social e cultural.

O método de análise dos dados prioriza a técnica da análise de conteúdo proposta por Bardin (2011). Os procedimentos metodológicos do trabalho seguem as três etapas descriminadas: 1) elemento fundamental da pesquisa: a interação entre o objeto de estudo e o pesquisador. Visitas técnicas aos espaços de agricultura urbana e periurbana em duas cidades do estado do Piauí: Floriano e Bom Jesus; 2) o registro de dados ou informações coletadas na pesquisa de campo: Definição dos espaços de pesquisa nas cidades e dos entrevistados disponíveis a participar da atividade cientifica de pesquisa; 3) a interpretação / explicação do pesquisador: Análise dos dados com o apoio teórico dos trabalhos científicos, com a caracterização dos espaços e com os objetivos de cada tipo de atividade produtiva agrícola (trabalho, renda, e produção de alimentos). Foram exploradas as manifestações representadas Sociedade e Território - Natal. Vol. 29, N. 2, p. 132-153, Jul./Dez. de 2017. 
por percepções, opiniões, crenças, sentidos para os artefatos materiais utilizando-se dos princípios e pressupostos da análise de conteúdo. Em seguida, na apresentação dos resultados, fez a revisão dos conceitos e dos pressupostos.

\section{CARACTERIZAÇÃO DAS ÁREAS DE ESTUDO}

\section{Hortas periurbanas em Bom Jesus (PI)}

A cidade de Bom Jesus, localizada a $640 \mathrm{~km}$ de Teresina (PI), ocupa posição privilegiada, uma vez que a região apresenta planície, com extensas áreas de cerrados, vales e baixões, propícias à agricultura e à pecuária. Bom Jesus (PI), geograficamente encontra-se situada na região do Vale do Rio Gurgueia, no sul do Estado do Piauí, limitando com os municípios de Currais e Santa Luz, ao norte; Gilbués, Monte Alegre, Redenção do Gurgueia, ao sul; Santa Luz, Guaribas, Morro Cabeça do Tempo, a leste; Baixa Grande do Ribeiro e Gilbués, ao oeste. De acordo com a estimativa do Instituto Brasileiro de Geografia e Estatística - IBGE (2017), a população da cidade de Bom Jesus está estimada em 24.532 habitantes, com uma área de 5.469.156 Km².

O município de Bom Jesus (PI), recentemente despontou, na mídia nacional, como "nova fronteira agrícola", o que o faz vivenciar um momento de crescimento significativo no setor agropecuário, que consequentemente, impulsiona os setores da educação, saúde, contabilidade, lazer, agroindústria e comércio em geral. A economia local é representada pelo comércio, pela agricultura e pela pecuária, fomentados pelo agronegócio, o que tem se revestido em crescimento substancial de todos esses setores, fazendo desta, uma região promissora, que vem atraindo pessoas de todas as partes do país.

A Prefeitura de Bom Jesus e o Serviço Brasileiro de Apoio a Micro e Pequenas Empresas (SEBRAE) atuaram nas proximidades da comunidade Eugenópolis, a 15 quilômetros do centro da cidade, para desenvolver a atividade de hortas comunitárias. Primeiramente, foi cedida por um proprietário uma área para o desenvolvimento da agricultura familiar. Durante dois anos, os horticultores cuidaram de parcelas individuais de terra e desenvolveram a atividade agrícola. Após esta iniciativa, eles decidiram atuar nas suas propriedades, próximas a este local.

Na comunidade de Eugenópolis, no sul do estado do Piauí, foram identificadas doze hortas. São propriedades adquiridas no mercado imobiliário ou resultado de heranças. As residências que abrigam as famílias (pais, filhos, irmãos) fazem parte da propriedade. Não são 
caracterizadas como hortas comunitárias e nem familiares, pois o dono da terra é autônomo e trabalha para satisfazer a demanda de mercado da cidade.

Cada proprietário tem uma gleba com diversos canteiros, e nela há uma variedade de hortaliças. Em sua maioria utilizam tela sombrite como cobertura para os canteiros, com a finalidade de manter a temperatura ideal e possuem uma extensão de terra que varia de três a quatorze hectares e o cultivo é feito em uma extensão entre um e um e meio hectare.

$\mathrm{Na}$ cidade, o ano todo, a temperatura varia entre 32 e 35 graus Celsius com duas estações anuais bem definidas: inverno e verão.

São cultivadas hortaliças com as tecnologias da irrigação por micro aspersor e irrigações suspensas e um dos horticultores alega usar produto industrializado a base de água para proteção das folhagens. Duas hortas fazem a molhagem com mangueira e regador. Cada propriedade possui poço de captação de água através de bombas submersas.

$\mathrm{Na}$ adubação, os horticultores preferem utilizar o esterco de gado, que é bastante lavado para tirar o excesso de urina dos animais, a fim de evitar a queima das hortaliças, além de pó de serra, os quais são misturados e depositados no canteiro durante um período de tempo para maturar. Uma das funções da serragem é conter o respingo da água e areia sobre as folhas no momento da irrigação e das precipitações, evitando assim dano as folhagens. $\mathrm{Na}$ sequência, são plantadas as hortaliças.

No inverno, há queda na produção por causa das fortes chuvas que danificam as plantas. Plantam simultaneamente cebolinha verde, salsa, coentro, alface, agrião, couve, rúcula, pimentão e plantas medicinais como erva cidreira, hortelã, gengibre, manjericão, arruda, boldo e alecrim. Três produtores cultivam macaxeira, milho e quiabo.

A comercialização é feita nas próprias hortas e também em pequenos mercados, feiras livres e restaurantes situados no meio urbano. Há feirantes que compram os produtos dos horticultores, há horticultores que têm barraca na feira. Pequena parte da produção é consumida pelos horticultores.

\section{Horta periurbana em Floriano (PI)}

A cidade de Floriano é originária do desmembramento de fazendas de gado da coroa Portuguesa que em 1676 foram doadas ao sertanista português Domingo Afonso Mafrense. Posteriormente, em 1873, já na condição de vila, passou a ser administrada pelo governo da província do Piauí com o nome de Colônia Rural de São Pedro de Alcântara, sendo oficialmente elevada a condição de cidade pela Lei Estadual n. 144 de 08 de julho de 1897. O Sociedade e Território - Natal. Vol. 29, N. 2, p. 132-153, Jul./Dez. de 2017. 
nome Floriano foi uma homenagem ao Marechal do Exército Brasileiro Floriano Vieira Peixoto.

Geograficamente a cidade de Floriano localiza-se no centro sul do Estado do Piauí na região do Médio Parnaíba. Faz fronteira ao sul com o município de Itaueiras (PI); ao norte com a cidade de Barão de Grajaú (MA); a leste com Francisco Ayres (PI), Nazaré do Piauí (PI), São Francisco do Piauí (PI) e São José do Peixe (PI) e a oeste com o município de Jerumenha (PI). É banhada em toda margem direita pelo Rio Parnaíba. De acordo com dados do IBGE (2016), Floriano ocupa uma área de 3.409,664 Km2 e possui uma população estimada de 58.803 habitantes.

O município de Floriano tinha 57690 habitantes no último Censo (2010). Isso coloca o município na posição 5 dentre 224 do mesmo estado. Em comparação com outros municípios do Brasil, fica na posição 520 dentre 5570. Sua densidade demográfica é de 16,.92 habitantes por quilômetro quadrado, colocando-o na posição 62 de 224 do mesmo estado. Quando comparado com outros municípios no Brasil, fica na posição 3572 de 5570 (INSTITUTO BRASILEIRO DE GEOGRAFIA E ESTATÍSTICA, 2017).

A economia do município de Floriano apoia-se no setor do comércio atendendo ao um grande número de cidades de sua macrorregião. A cidade também se destaca como um desenvolvido polo educacional formado por uma rede de estabelecimentos de ensino que contemplam desde a educação infantil até a pós-graduação e atrai para a cidade um grande número de estudantes de todas as regiões do país.

O modelo de hortas urbanas e periurbanas na cidade de Floriano tem sua origem em projetos comunitários desenvolvidos pela Cáritas Brasileira. A Cáritas Brasileira trata-se de uma organização filantrópica fundada em 1956 e está vinculada à Confederação Nacional dos Bispos do Brasil (CNBB). Integra uma rede de filantropia internacional composta por 162 organizações com atuação em 200 países e territórios do mundo.

No município de Floriano, a Cáritas Brasileira atua desde a década de 1990, denominada Cáritas Diocesana de Floriano que promove ações relacionadas à Economia Popular Solidária (EPS). A EPS é uma estratégia de desenvolvimentos sustentável solidária que envolve os processos associados e coletivos de trabalho e cooperativado com especial interesse em melhorar a qualidade de vida das pessoas, além de combater as desigualdades sociais de indivíduos e comunidades em situação de vulnerabilidade social (CASTRO; GUSMÃO, 2016). 
Em outubro de 1999, a Cáritas Diocesana de Floriano ajudou a implantar a horta comunitária Morro do Tiro na comunidade de mesmo nome situada na zona urbana do município de Floriano. O terreno da Horta Comunitária do Morro do Tiro, conhecida como Horta “Dona Betinha”, está situada à Rua Adelina Monteiro, n. 540, Campo Velho, cidade de Floriano (PI).

O processo de implantação da Horta Comunitária se deu em parceria com a comunidade e envolveu a cessão de um terreno pertencente à Diocese de Floriano, bem como, a perfuração de um poço tubular para garantir o acesso à água e; a doação das principais ferramentas para começar a produção. Além disso, coube a Cáritas Diocesana de Floriano a formação, planejamento e capacitação dos grupos da comunidade que iriam realizar o trabalho com as hortas.

Inicialmente foram selecionadas e cadastradas 27 famílias em situação de exclusão social residentes na área de abrangência da Paróquia de Santana. As famílias passaram a trabalhar diretamente nos canteiros e a produzir alimentos orientados para uma produção orgânica. Embora ocupassem o mesmo terreno, os canteiros foram demarcados de modo que cada família ocupou apenas o espaço individualizado que lhe foi destinado. Cada horticultor tem de um a dez canteiros. São cultivadas diversas hortaliças de acordo com a escolha de cada produtor agrícola. Vinte por cento das áreas cultiváveis foram cobertas com tela de sombrite para manter a temperatura adequada dos canteiros com extensão variando entre um e um e meio hectares.

Posteriormente, as famílias cadastradas se organizaram em forma de associação. É fundada a Associação de Pequenos Produtores de Hortaliças do Morro do Tiro. Cada produtor passou a contribuir com um valor mensal destinado basicamente ao custeio da energia do local das hortas, além de atribuições da própria associação e, eventualmente, para doações a outras comunidades necessitadas. De acordo com a diocese de Floriano, todas as pessoas interessadas devem ser acolhidas e integradas. Neste caso, um dos aposentados faz a doação de um canteiro.

A comercialização da produção é feita em grande parte na própria horta, local da atividade agrícola. Há também a realização de feiras livres na sede da Arquidiocese de Floriano, no centro da cidade, onde é vendida outra parte da produção. Outra parte abastece alguns restaurantes situados no meio urbano da cidade. Por fim, uma pequena parte da produção é consumida pelos próprios horticultores e seus familiares. 
Até o ano de 2013, os produtores da horta comunitário Morro do Tiro tiveram garantidos a compra de $50 \%$ de sua produção como parte de um convênio entre a associação de produtores e a Companhia Nacional de Abastecimento (CONAB) através do Programa Aquisição de Alimentos (PAA) do governo federal. Com o fim do convênio, a associação encaminhou um novo projeto de continuação da parceria anteriormente firmada. Este, por sua vez, encontra-se em fase de análise e aguardando liberação pelos órgãos responsáveis.

Conforme os horticultores pesquisados, não utilizam nenhum tipo de agrotóxicos. Fazem uso do esterco de gado, folha de carnaúba, os quais são misturados e depositados no canteiro para maturação. A função da folhagem é conter o respingo da água e areia sobre as hortaliças no momento da irrigação e das chuvas. Na sequência, é preparada a terra, aplicado a mistura, para plantar as hortaliças.

Cultivam, simultaneamente, acelga, cebolinha verde, salsa, coentro, alface, agrião, couve, rúcula, pimentão, quiabo e plantas medicinais como: erva cidreira, hortelã, gengibre, manjericão, arruda, boldo, malva do reino e alecrim. Três produtores cultivam macaxeira, milho e quiabo.

\section{RESULTADOS E DISCUSSÕES}

\section{Perfil dos horticultores piauienses}

Para estabelecer o perfil dos horticultores integrantes da pesquisa foi feita uma análise estatística das variáveis: sexo, faixa etária, escolaridade, faixa de renda, situação trabalhista, atividade anterior, tempo de trabalho na horta e carga horária semanal de trabalho. Participaram do estudo 10 horticultores que residem em municípios piauienses e desenvolvem suas atividades em hortas situadas em áreas urbanas e periurbanas. Foram entrevistados 6 horticultores no município de Bom Jesus e 4 no município de Floriano.

Conforme Gorz (2005, p. 62), “a fonte da riqueza é a atividade que desenvolve as capacidades humanas, a saber: o 'trabalho' de produção de si que 'os indivíduos' - cada um e todos, cada qual nas suas trocas multilaterais com os outros - realizam sobre si mesmos". Percebe-se que existem pequenos compartilhamentos de saberes e conhecimentos entre os horticultores sobre os cuidados no cultivo de determinas espécies de vegetais que possuem lotes num mesmo quarteirão, contudo, eles relatam que realizam trabalhos manuais sozinhos, em certos períodos um familiar vem ajudar de vez em quando. 
Tabela 1: Distribuição do número de horticultores, em números absolutos e relativos, segundo sexo, para os municípios do Estado do Piauí - Brasil - 2017

\begin{tabular}{cccccc}
\hline \multirow{2}{*}{ SEXO } & \multirow{2}{*}{ TOTAL } & \multicolumn{2}{c}{ MASCULINO } & \multicolumn{3}{c}{ FEMININO } \\
& & $\mathrm{N}$ & $\%$ & $\mathrm{~N}$ & $\%$ \\
\hline \hline Bom Jesus & 6 & 5 & 83 & 1 & 17 \\
Floriano & 4 & 2 & 50 & 2 & 50 \\
\hline
\end{tabular}

Fonte: Elaborada pelos autores.

Na Tabela 1, verificou-se que no município de Bom Jesus, regista-se uma ligeira diferença entre a população do sexo masculino, 5 (83\%), em relação à feminina, 1 (17\%). Contudo, em Floriano, em relação às pessoas que aceitaram participar da pesquisa, existem 2 (50\%) horticultores para ambos os sexos.

No instrumento de coleta de dados começamos pela faixa etária a partir de 18 anos de idade. De acordo com o Estatuto da Criança e do Adolescente (ECA), a idade cronológica de 18 anos como limite de maioridade (BRASIL, 1995a). Para cada faixa etária utilizamos o intervalo de 15 anos de idade, entretanto na primeira faixa retiramos dos 15 aos 17, o que reduz para 12 anos de idade. Da faixa de 18 a 29 não houve entrevistados.

Quanto ao sexo, na Tabela 1, percebeu-se a maior prevalência do sexo masculino no trabalho de horticultor na cidade de Bom Jesus, 5 (83\%). De acordo com Schmit e Santos (2013), o trabalho na agricultura ainda reproduz a estrutura patriarcal da família. O patriarcado atribui ao homem o papel de protagonista no processo de produção agrícola e desvaloriza o trabalho da mulher. Contudo, estudos realizados em hortas urbanas e periurbanas (OTTMANN et al., 2010; PRIMO et al., 2014) retratam um novo cenário onde prevalece o equilíbrio na divisão do trabalho entre homens e mulheres como ocorre na cidade de Floriano. Tal fato se deu especialmente pela inserção da família - maridos, mulheres e filhos - no processo de produção da agricultura urbana. Na tabela 2, exibem-se as faixas etárias dos horticultores piauienses:

Tabela 2: Distribuição do número de horticultores, em números absolutos e relativos, segundo faixa etária, para os municípios do Estado do Piauí - Brasil - 2017

\begin{tabular}{cccccccc}
\hline \multirow{2}{*}{ FAIXA ETÁRIA } & \multirow{2}{*}{ TOTAL } & \multicolumn{2}{c}{ DE 30 A 44 } & \multicolumn{2}{c}{ DE 45 A 59 } & \multicolumn{2}{c}{ DE 60 OU MAIS } \\
& & $\mathrm{N}$ & $\%$ & $\mathrm{~N}$ & $\%$ & $\mathrm{~N}$ & $\%$ \\
\hline \hline Bom Jesus & 6 & 3 & 50 & 3 & 50 & - & - \\
Floriano & 4 & - & - & 2 & 50 & 2 & 50 \\
\hline
\end{tabular}

Fonte: Elaborada pelos autores. 
A maioria dos entrevistados, na tabela 2, $5(50 \%)$ encontrava-se na faixa etária dos 45 a 59 anos. Para Bom Jesus, 3 (50\%) estavam na faixa de 30 a 44 e os outros 3 (50\%) na faixa de 45 a 59 anos de idade. No caso de Floriano, a população de horticultores tinha mais idade das faixas de 45 e mais: 2 (50\%) na faixa de 45 a 59 anos e 2 (50\%) de 60 anos ou mais.

$\mathrm{Na}$ distribuição de horticultores quanto à faixa etária, observa-se a prevalência de trabalhadores com idade acima dos 45 anos (50\%). Mesmo com a inserção da família na agricultura urbana, o resultado mostra uma tendência de pessoas mais jovens não participarem dessa atividade. Matte, Spanevello e Azevedo (2010), em parte explicam esse fenômeno ao concluir um estudo que mostra o pouco interesse de filhos de agricultores em seguir a profissão do pai.

De acordo com Brumer (2006), prevalece por parte dos jovens a ideia de que a atividade agrícola, sobretudo no meio rural é desvalorizada e propicia poucos benefícios para seus praticantes. Adota-se como pressuposto que essa mesma lógica sucessória se reproduza no meio urbano.

Observa se que a maior parte dos horticultores possui mais de 30 anos de idade, o que nos leva a concluir que essa não é uma atividade atrativa para os adolescentes e jovens. A seguir, na tabela 3, revela sobre os horticultores piauienses serem ou não aposentados:

Tabela 3: Distribuição do número de horticultores, em números absolutos e relativos, segundo aposentadoria, para os municípios do Estado do Piauí - Brasil - 2017

\begin{tabular}{|c|c|c|c|c|c|}
\hline \multirow[b]{2}{*}{ APOSENTADO } & \multirow[b]{2}{*}{ TOTAL } & \multicolumn{2}{|c|}{ SIM } & \multicolumn{2}{|c|}{ NÃO } \\
\hline & & $\mathrm{N}$ & $\%$ & $\mathrm{~N}$ & $\%$ \\
\hline Bom Jesus & 6 & - & - & 6 & 100 \\
\hline Floriano & 4 & 1 & 25 & 3 & 75 \\
\hline
\end{tabular}

Fonte: Elaborada pelos autores.

Em relação à faixa etária dos horticultores, há uma maior predominância de horticultores com idade já elevada, estando os horticultores em sua maioria com idade igual ou superior 45 anos, como pode ser observado na Tabela 3, tendo nesse universo apenas um $(10 \%)$ aposentado.

Dessa forma, pode-se constatar que a maioria dos horticultores se encontra ainda em idade produtiva, uma vez no município de Bom Jesus, 5 dos horticultores encontram-se com idade entre 45 e 59 anos e ainda não sendo aposentados, como pode ser observado nas 
Tabelas 2 e 3. No universo de pesquisa foram encontrados dois horticultores já com idade superior a 60 anos, contudo ainda não conseguiram se beneficiar da aposentadoria.

Observa-se aqui o processo de envelhecimento da atividade agrícola, pois é predominante o exercício do trabalho manual cada vez mais por pessoas com idade avançada. Durante as entrevistas, revelaram o desinteresse dos seus filhos pela horticultura.

Há ainda a necessidade de elaboração de políticas públicas objetivando tornar a agricultura urbana mais atrativa para todos os entes familiares, buscando também elevar sua contribuição econômica para essas famílias e, também, para o mercado.

Optou-se, na Tabela 4, por não apresentar nas colunas as variáveis: Sem Escolaridade, Fundamental Completo, Superior Incompleto e Superior Completo, devido não ter sido entrevistado nenhum horticultor dentro desses níveis de estudo/ensino.

Tabela 4: Distribuição do número de horticultores, em números absolutos e relativos, segundo a escolaridade, para os municípios do Estado do Piauí - Brasil - 2017

\begin{tabular}{lccccccc}
\hline $\begin{array}{c}\text { ESCOLARIDA } \\
\text { DE }\end{array}$ & TOTAL & \multicolumn{2}{c}{ FUNDAMENTAL } & \multicolumn{2}{c}{ ENSINO MÉDIO } & \multicolumn{2}{c}{ ENSINO MÉDIO } \\
& & $\mathrm{N}$ & $\%$ & $\mathrm{~N}$ & $\%$ & $\mathrm{~N}$ & $\%$ \\
\hline \hline Bom Jesus & 6 & 5 & 83 & 1 & 17 & - & - \\
Floriano & 4 & 1 & 25 & 2 & 50 & 1 & 25 \\
\hline
\end{tabular}

Fonte: Elaborada pelos autores.

O grau de escolaridade dos horticultores dos municípios pesquisados está distribuído em três níveis de ensino Fundamental Incompleto, Ensino Médio Incompleto e Ensino Médio Completo: 5 (83\%) dos horticultores de Bom Jesus possuem somente o ensino Fundamental incompleto e apenas 1(17\%) possui o Ensino Médio Incompleto. Já no Município de Floriano, o nível de escolaridade é bastante variável conforme pode ser visto na Tabela 4.

A maior concentração de horticultores do município de Bom Jesus no nível Fundamental de Ensino pode ser justificada por residirem em uma comunidade periurbana e, também, pela sua faixa etária, conforme observado na Tabela 2. Tais dados indicam que a questão da educação periurbana ainda é um problema a ser resolvido. Considerando que, no campo e na área periurbana, há um grande número de famílias que, por razões adversas, não conseguem completar todo o ciclo da educação básica.

O baixo grau de escolaridade formal no meio rural é um dos fatores principais que dificulta o processo de inovação tecnológica, e ele aumenta de importância quando se verifica a existência de pessoas não alfabetizadas. 
Pode-se concluir que o grau de instrução dos agricultores é relativamente baixo, embora sejam encontrados horticultores piauienses com Ensino Médio. Segundo Gorz (2005, p. 32), “[...] o saber é aprendido quando a pessoa o assimilou ao ponto de esquecer que teve de aprendê-lo". Verifica-se que todos os horticultores executam atividades de cavar, de adubar, de semear, de irrigar a terra, utilizando sementes ou raízes específicas, estrume de bode e palha de carnaúba. Verifica-se, na tabela 4 , a renda.

\begin{tabular}{|c|c|c|c|c|c|c|c|}
\hline \multirow{2}{*}{ RENDA } & \multirow{2}{*}{ TOTAL } & \multicolumn{2}{|c|}{ MENOS DE $1 \mathrm{SM}^{*}$} & \multicolumn{2}{|c|}{ ENTRE 1 E 2 SM* } & \multicolumn{2}{|c|}{ ENTRE 2 E 3 SM* } \\
\hline & & $\mathrm{N}$ & $\%$ & $\mathrm{~N}$ & $\%$ & $\mathrm{~N}$ & $\%$ \\
\hline Bom Jesus & 6 & - & - & 3 & 50 & 3 & 50 \\
\hline Floriano & 4 & 4 & 100 & - & - & 0 & - \\
\hline
\end{tabular}

Observa-se que a renda média dos horticultores entrevistados, segundo tabela 5, está acima de um salário mínimo por mês. No município de Bom Jesus, 50\% dos horticultores possuem renda média de 1 a 2 salários mínimos por mês, enquanto $50 \%$ tem renda média de 2 a 3 salários mínimos por mês. Já no município de Floriano, 100\% dos entrevistados tem renda média de menos de um salário mínimo. Destaca-se, como fator que pode interferir diretamente na renda obtida, o tempo dedicado às atividades nas hortas, conforme pode ser observado na Tabela 7, em que no município de Floriano 10\% dos horticultores destinam no máximo 4 horas. No município de Bom Jesus, 50\% dos horticultores destinam de 4 a 8 horas diárias nas hortas e $33 \%$ mais de 8 horas diárias de atividades.

Outro fator que pode justificar a diferença na renda dos horticultores é que no município de Bom Jesus todo pequeno produtor agrícola tem a horticultura como única atividade laboral, dedicando- se totalmente a ela para o seu sustento, entretanto, no município de Floriano os horticultores dividem suas atividades nas hortas com outras atividades profissionais. Soma-se a isso, o fato dos horticultores de Bom Jesus residir próximo ou mesmo nos terrenos das hortas, o que facilita o envolvimento nas atividades diárias desenvolvidas nas hortas.

O tipo de comercialização praticada pelos horticultores em ambos os municípios é feita diretamente pelos horticultores em feiras livres ou no mercado público, o que agrega valor aos seus produtos, a outra parte é fornecida a Supermercados e Restaurantes do município.

Sociedade e Território - Natal. Vol. 29, N. 2, p. 132-153, Jul./Dez. de 2017. 
Além disso, em relação à renda obtida pelos participantes da pesquisa, percebem-se dificuldades de sua mensuração em virtude da forma de comercialização na própria horta pelos horticultores, não havendo um controle da arrecadação quando esse fato ocorre. Abaixo, a tabela 6, expressa se os horticultores exercem uma segunda atividade laboral:

Tabela 6: Distribuição do número de horticultores, em números absolutos e relativos, segundo atividade anterior, para os municípios do Estado do Piauí Brasil - 2017

\begin{tabular}{lccccc}
\hline $\begin{array}{c}\text { ATIVIDADE } \\
\text { ANTERIOR }\end{array}$ & TOTAL & \multicolumn{2}{c}{ AGRICULTOR } & \multicolumn{2}{c}{ OUTRA OCUPAÇÃO } \\
\hline \hline Bom Jesus & & $\mathrm{N}$ & $\%$ & $\mathrm{~N}$ & $\%$ \\
\hline Floriano & 6 & 2 & 33 & 4 & 66 \\
\hline
\end{tabular}

Fonte: Elaborada pelos autores.

Dos participantes da pesquisa investigados, apenas dois tem origem rural, ou seja, moravam e trabalhavam antes no meio rural, estando há mais de 15 anos envolvidas com atividades manuais em hortas. Pode-se observar, na Tabela 8, que o tempo de dedicação às atividades nas hortas da maioria dos participantes da pesquisa, está acima de 10 anos. Embora parte dos horticultores pesquisados exerça ou tenham exercido outras profissões há uma evidente identificação dos mesmos com a horticultura urbana.

Conclui-se, com base nos dados e nas observações, que se os horticultores pesquisados são produtores agrícolas de pequeno porte, ou exercem outras atividades. Por estarem a muito tempo na atividade rural, reforça a percepção de que esses horticultores querem usufruir das vantagens oferecidas para a agricultura urbana e periurbana, não sendo, portanto, por falta de opção. A análise das atividades desenvolvidas por esses produtores antes ou em paralelo com a horticultura reforça essa análise, conforme pode ser visto na Tabela 7.

Tabela 7 - Distribuição do número de horticultores, segundo atividade exercida antes ou em paralelo com a horticultura, para os municípios do Estado do Piauí - Brasil - 2017

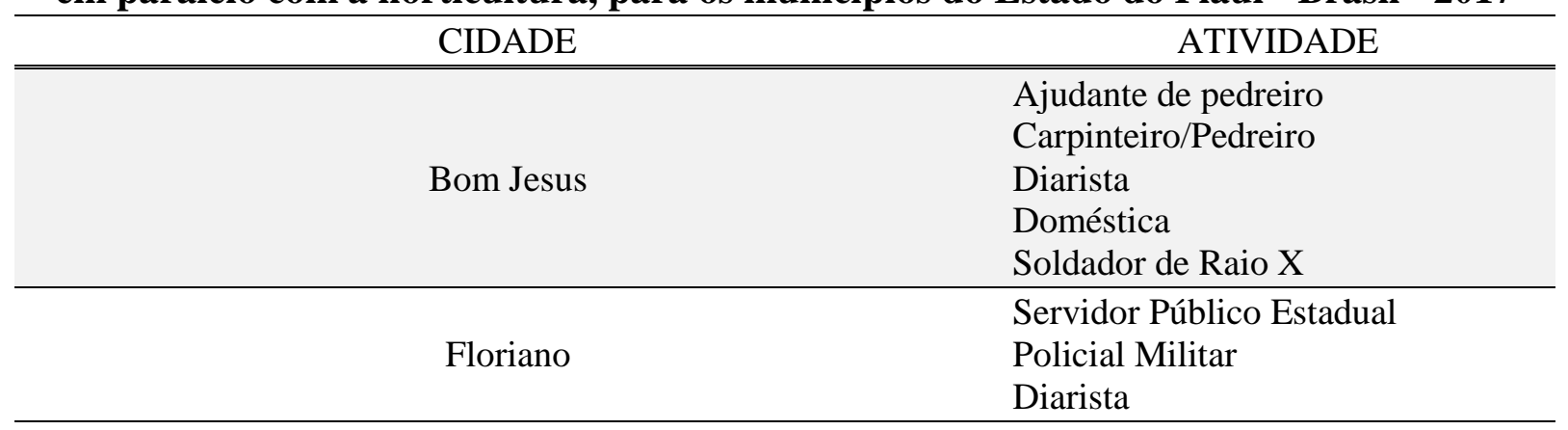

Fonte: Elaborada pelos autores

Sociedade e Território - Natal. Vol. 29, N. 2, p. 132-153, Jul./Dez. de 2017. 
Conforme os horticultores, as outras atividades laborais se devem a necessidade de complementar à renda familiar. Em sequência, na tabela 8, esclarece o tempo de trabalho nas hortas:

Tabela 8: Distribuição do número de horticultores, em números absolutos e relativos, segundo o tempo de trabalho, para os municípios do Estado do Piauí - Brasil - 2017

\begin{tabular}{lcccccccccc}
\hline \multirow{2}{*}{$\begin{array}{c}\text { TEMPO DE TRABALHO DA } \\
\text { HORTA }\end{array}$} & \multicolumn{3}{c}{ TOTAL } & \multicolumn{2}{c}{ ATÉ 05 } & \multicolumn{2}{c}{ DE 06 A } & \multicolumn{2}{c}{ DE 11 A } & \multicolumn{2}{c}{ MAIS DE 15 } \\
& & $\mathrm{N}$ & $\%$ & $\mathrm{~N}$ & $\%$ & $\mathrm{~N}$ & $\%$ & $\mathrm{~N}$ & $\%$ \\
\hline \hline Bom Jesus & 6 & 1 & 17 & 2 & 33 & 1 & 17 & 2 & 33 \\
\hline Floriano & 4 & - & - & 2 & 50 & - & - & 2 & 50 \\
\hline
\end{tabular}

Fonte: Elaborada pelos autores.

$\mathrm{Na}$ análise do tempo de trabalho na agricultura urbana e periurbana, conforme Tabela 8, percebe-se que os horticultores exercem essa atividade há mais de 6 anos (90\%). Portanto, não se trata do exercício de uma atividade provisória ou temporária. A seguir, a tabela 9 revela a carga horária de trabalho nas hortas:

Tabela 9: Distribuição do número de horticultores, em números absolutos e relativos, segundo a Carga horária de trabalho, para os municípios do Estado do Piauí - Brasil - 2017

\begin{tabular}{lccccccc}
\hline $\begin{array}{c}\text { CARGA HORÁRIA } \\
\text { DIÁRIA DE }\end{array}$ & TOTAL & \multicolumn{2}{c}{ ATÉ 4 H } & \multicolumn{2}{c}{ MAIS DE 4 H A 8 } & \multicolumn{2}{c}{ MAIS DE 8 H } \\
\multicolumn{1}{c}{ TRABALHO } & $\mathrm{N}$ & $\%$ & $\mathrm{~N}$ & $\%$ & $\mathrm{~N}$ & $\%$ \\
\hline \hline Bom Jesus & 6 & 1 & 17 & 3 & 50 & 2 & 33 \\
\hline Floriano & 4 & 4 & 100 & - & - & - & - \\
\hline
\end{tabular}

Fonte: Elaborada pelos autores.

Quanto à carga horária de trabalho diária, de acordo com a Tabela 9, os resultados mostram que os horticultores urbanos e periurbanos dedicam, no mínimo, 4 horas por dia no desenvolvimento de suas atividades (100\%). Desses, parte deles $(33 \%)$, chega a permanecer mais de oito (8) horas diárias no trabalho. É o caso da cidade de Bom Jesus-PI onde os processos de trabalho envolvem o uso de tecnologias de irrigação tais como irrigação por aspersores, suspensa e por sulcos que intensificam a produção.

$\mathrm{Na}$ cidade de Floriano-PI, os horticultores cultivam pequenas áreas e a produção atende a uma demanda restrita. Para esses horticultores, o tempo dedicado ao trabalho com hortas chega, no máximo, há 4 horas por dia. O tempo dedicado pelo horticultor no trabalho com hortas revela em parte o vínculo e o compromisso com a atividade que exerce. Também 
pode estar associado ao tamanho do empreendimento ou com possíveis dificuldades associadas a seu exercício profissional. É caso do processo de irrigação manual das hortas na cidade de Floriano-PI.

Tal prática exige um grande esforço físico e demanda maior tempo na execução dessa atividade. De acordo com Barth et al. (2016), "a agricultura de pequeno porte caracteriza-se pela pouca automatização de seus processos, fato que demanda cargas excessivas de trabalho em seus praticantes". As condições de trabalho do horticultor urbano e periurbano nas cidades de Bom Jesus e Floriano têm como referência de análise as categorias "condições físicas e materiais" e suas subcategorias propostas Borges et al. (2015).

Os espaços públicos e/ou privados utilizados como áreas de produção coletiva na horticultura urbana e periurbana situam-se geralmente em locais com baixa densidade populacional e fácil acesso a água. Eles abrigam um modelo de agricultura de viés sustentável que se utiliza de tecnologias verdes que não agridem o meio ambiente e produzem alimentos saudáveis, livres de agrotóxicos e outros produtos químicos. Embora na horticultura urbana e periurbana os espaços individuais de cultivo sejam pequenos, o uso de ferramentas manuais e a exposição prolongada a fatores climáticos, dentre outros são ocorrências que representam potenciais riscos à saúde do horticultor.

Os horticultores necessitam de treinamentos para fortalecer as informações sobre as condições de trabalho de produtores agrícola, tais como:

\footnotetext{
(por exemplo, nos temas agrotóxicos, maquinas e equipamentos, riscos com eletricidade, animais peçonhentos, ferramentas, silos e armazéns, transporte de trabalhadores, fatores climáticos e topográficos, áreas de vivência, ergonomia e organização do trabalho); noções de primeiros socorros; noções de prevenção de DST, AIDS e dependências químicas; noções sobre legislação trabalhista e previdenciária relativa à Segurança e Saúde no Trabalho; noções sobre prevenção e combate a incêndios; princípios gerais de higiene no trabalho; relações humanas no trabalho. (BRASIL, 2005, 2011).
}

Percebeu-se que os horticultores piauienses necessitam de reorientações sobre uso diário de equipamentos de proteção individual, formas de manejo do solo, prevenção de pragas com defensivos orgânicos, noções de ergonomia, de relações humanas e de primeiros socorros.

\section{CONSIDERAÇÕES FINAIS}

As condições de trabalho do horticultor urbano e perirubano permitem a produção de alimentos que atende uma pequena demanda. Vale ressaltar a importância das hortas para Sociedade e Território - Natal. Vol. 29, N. 2, p. 132-153, Jul./Dez. de 2017. 
geração de renda para os horticultores e abastecimento urbano. No caso de Bom Jesus, além de contribuir para a produção de alimentos no meio urbano, as hortas são formas de fixar as famílias na propriedade.

No entanto, apesar de ser vista como uma atividade lucrativa por alguns, a agricultura familiar enfrenta problemas como a falta de mão de obra qualificada, ausência de insumos e até mesmo de assistência técnica especializada, além de políticas públicas que atendam realmente às suas necessidades socioeconômicas e culturais. A comercialização da produção sofre com as oscilações de mercado e os produtos são valorados de acordo com a oferta e a demanda. Muitas vezes, os horticultores vendem seus produtos por um preço mais baixo para atravessadores por não terem condições de venderem sua produção em feiras e estabelecimentos comerciais. Quando há quebra de produção no período de maior precipitação na região, fica destacada a falta de uma estrutura adequada nos em locais de produção.

Para que a produção e comercialização da produção agrícola urbana alcance maior rentabilidade, é preciso que os horticultores sejam orientados no sentido de se tornarem feirantes, de entender melhor sobre finanças pessoais e endividamento, e de melhorar a qualidade de seus produtos.

\section{REFERENCIAS}

A MORTE DO MAR. Correio da Manhã, Guanabara, RJ, 5 dez. 1969. Caderno 1, p. 19.

BARCELOS, Fábio. A Coroa pelo bem da agricultura e do comércio: a importância institucional da Coroa portuguesa na formação da agricultura brasileira durante o período colonial. Rio de Janeiro: Arquivo Nacional, 2010. (Publicações Históricas; n. 97).

BARDIN, Laurence. Análise de Conteúdo. Tradução Luís Antero Reto, Augusto Pinheiro. São Paulo: Edições 70, 2011.

BARTH, Michele et al. Agricultura Familiar: características ergonômicas das atividades e impactos na saúde dos trabalhadores. Estudos Sociedade e Agricultura, v. 24, n. 2, 2016.

BORGES et al. Condições de trabalho. In: BENDASSOLLI, Pedro Fernando; BORGESANDRADE, Jairo Eduardo (Org.). Dicionário brasileiro de psicologia do trabalho e das organizações. São Paulo: Casa do Psicólogo, 2015. p. 227-236.

BRASIL. Conselho Nacional dos Direitos da Criança do Adolescente. Estatuto da Criança e do Adolescente Hospitalizado. Resolução n. 41 de 13 de outubro de 1995, aprova em sua íntegra o texto oriundo da Sociedade Brasileira de Pediatria, relativo aos Direitos da Criança e do Adolescente hospitalizados. Diário Oficial [da] República Federativa do Brasil, Poder Executivo, Brasília, DF, 17 out. 1995a. Seção 1, p. 16319-16320. 
Decreto n. 1.366, de 12 de janeiro de 1995. Dispõe sobre o Programa Comunidade Solidária e dá outras providências. Diário Oficial [da] República Federativa do Brasil, Poder Executivo, Brasília, DF, 13 jan. 1995b. Seção 1, p. 665.

Ministério do Trabalho e Emprego. Portaria n. 86, de 03 de março de 2005. Aprova a Norma Regulamentadora de Segurança e Saúde no Trabalho na Agricultura, Pecuária, Silvicultura, Exploração Florestal e Aquicultura. Diário Oficial [da] República Federativa do Brasil, Poder Executivo, Brasília, DF, 04 mar. 2005. Seção 1, p. 105-110.

Portaria n. 2.546, de 14 de dezembro de 2011. Aprova a Norma Regulamentadora de Segurança e Saúde no Trabalho na Agricultura, Pecuária, Silvicultura, Exploração Florestal e Aquicultura. Diário Oficial [da] República Federativa do Brasil, Poder Executivo, Brasília, DF, 16 dez. 2011. Seção 1.

BRUMER, Anita. A Problemática dos Jovens Rurais na Pós-modernidade. In: Congreso LatinoAmericano de Sociología Rural, 7., 2006, Quito. Anais... Quito, Ecuador, nov. 2006.

CARVALHO, Marília Gomes de. Tecnologia e Sociedade. In: BASTOS, João Augusto. (Org.). Tecnologia \& Interação. Curitiba: CEFET/PR, 1998. cap. 5, p. 63-72.

CASTRO, Danilo; GUSMÃO, Cristina Rocha. Atuação da Cáritas em Floriano. Fundos Solidários: tecendo redes, entrelaçando vidas - Piauí, Brasília, DF, n. 1, p. 12-13, 2016.

COSTA, Patrícia Fernanda da. Agricultura Familiar e Sustentabilidade. 2016. 15 f. Monografia (Especialização em Cooperativismo Solidário e Crédito Rural)-Universidade Estadual do Centro Oeste do Paraná, Chopinzinho, 2016.

DERANI, Cristiane. Alimento e biodiversidade: fundamentos de uma normatização. Hiléia: Revista de Direito Ambiental da Amazônia. Manaus, Ano 3, n. 4, p. 53-86, 2006.

DUNCK, Ellen Adeliane Fernandes Magni. Agrotóxicos e a intervenção do capital na agricultura. In: CONGRESSO NACIONAL DO CONPEDI - UFMG/FUMEC/DOM HELDER CÂMARA, 24. Direito agrário e agroambiental [Recurso eletrônico on-line]. Florianópolis, SC: CONPEDI, 2015. p. 49-65.

FARIAS, Alexandrina Benjamin Estevão de. O papel da agricultura familiar para a diversificação e valorização da produção de alimentos pós-revolução verde no Brasil. Revista de Direito Agrário e Agroambiental, Belo Horizonte, MG, v. 1, n. 2, p. 75-90, jul./dez. 2015.

FURTADO, Celso. Formação econômica do Brasil. 32. ed. São Paulo: Companhia Editora Nacional, 2003. (Biblioteca Universitária. Série 2. Ciências Sociais, v. 23).

GORZ, André. O imaterial: conhecimento, valor e capital. Tradução de Celso Azzan Júnior. São Paulo: Annablume, 2005.

HENRIQUES, Amilson Barbosa. A Moderna Agricultura no final do século XIX em São Paulo: algumas propostas. História, São Paulo, v. 30, n. 2, p. 359-380, ago./dez. 2011. 
INSTITUTO BRASILEIRO DE GEOGRAFIA E ESTATÍSTICA. Brasil em Síntese: Piauí: Floriano. Rio de Janeiro: IBGE, 2017.

MATOS, Alan Kardec Veloso. Revolução verde, biotecnologia e tecnologias alternativas. Cadernos da FUCAMP, v. 10, n. 12, p. 1-17, 2011.

MATTE, Alessandra; SPANEVELlO, Rosani Marisa; AZEVEDO, Letícia Fátima de. A reprodução social na agricultura familiar: saída dos filhos e o encaminhamento do patrimônio entre agricultores sem sucessores. In: CONGRESSO DA SOCIEDADE BRASILEIRA DE ECONOMIA ADMINISTRAÇÃO E SOCIOLOGIA RURAL, 48., 2010, Campo Grande. Anais... Campo Grande, MS: SOBER, 2010. p. 1-15.

MERCADANTE, Maurício. Da agricultura neolítica à segunda, revolução verde: a história e o contexto da criação de organismos transgênicos. Cadernos Aslegis, Brasília, DF, v. 3, n. 7 , p. 73-79, jan./abr. 1999.

ORGANIZAÇÃO DAS NAÇÕES UNIDAS PARA ALIMENTAÇÃO E AGRICULTURA. Alimentar o mundo, cuidar do planeta. Roma, Itália: FAO, 2014.

ORGANIZACIÓN DE LAS NACIONES UNIDAS PARA LA ALIMENTACIÓN Y LA AGRICULTURA. El estado mundial de la agricultura y la alimentacion: cambio climático, agricultura y seguridad alimentaria. Roma, Itália: FAO, 2016.

OTTMANN, Michelle Melissa Althaus et al. Impactos ambientais e sócio-econômicos em hortas comunitárias sob Linhas de Transmissão no Bairro Tatuquara, Curitiba, PR, Brasil. Revista Brasileira de Agroecologia, Porto Alegre, v. 5, n. 1, p. 86-94, 2010.

PRIMO, Gabriel Alves et al. Mapeamento e caracterização da agricultura urbana no municipio de Gurupi-TO. Revista Verde de Agroecologia e Desenvolvimento Sustentável, Pombal, PB, v. 9, n. 4, p. 212-219, 2014.

SCHMITZ, Aline Motter; DOS SANTOS, Roselí Alves. A produção de leite na agricultura familiar do Sudoeste do Paraná e a participação das mulheres no processo produtivo. Terr@ Plural, v. 7, n. 2, p. 339-356, 2014.

SERRA, Letícia Silva et al. Revolução Verde: reflexões acerca da questão dos agrotóxicos. Revista do CEDS, São Luiz, MA, v. 1, n. 4, p. 2-25, jan./jul. 2016.

\section{Recebido em Agosto de 2017}

Aprovado em Novembro de 2017

Publicado em Dezembro de 2017

Sociedade e Território - Natal. Vol. 29, N. 2, p. 132-153, Jul./Dez. de 2017. 